\title{
əIn Situ Measurements of Wind and Turbulence by a Motor Glider in the Andes
}

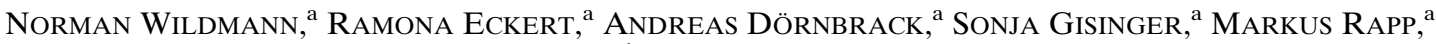 \\ KLAUS OHLMANN, ${ }^{\mathrm{b}}$ AND ANNELIZE VAN NIEKERK ${ }^{\mathrm{c}}$ \\ ${ }^{a}$ Deutsches Zentrum für Luft- und Raumfahrt e.V., Institut für Physik der Atmosphäre, Oberpfaffenhofen, Germany \\ ${ }^{\mathrm{b}}$ Quo Vadis, Serres, France \\ ${ }^{\mathrm{c}}$ Met Office, Exeter, United Kingdom
}

(Manuscript received 19 August 2020, in final form 20 January 2021)

\begin{abstract}
A Stemme S10-VT motor glider was equipped with a newly developed sensor suite consisting of a five-hole probe, an inertial navigation and global navigation satellite system, two temperature sensors, and a humidity sensor. By design, the system provides three-dimensional wind vector data that enable the analysis of atmospheric motion scales up to a temporal resolution of $10 \mathrm{~Hz}$. We give a description of components and installation of the system, its calibration, and its performance. The accuracy for the measurement of the wind vector is estimated to be on the order of $0.5 \mathrm{~m} \mathrm{~s}^{-1}$. As part of the Southern Hemisphere Transport, Dynamics, and Chemistry (SouthTRAC) field campaign, 30 research flights were performed from September 2019 to January 2020. We present statistical analysis of the observations, discriminating pure motor flights from soaring flights in the lee waves of the Andes. We present histograms of flight altitude, airspeed, wind speed and direction, temperature, and relative humidity to document the atmospheric conditions. Probability density functions of vertical air velocity, turbulence kinetic energy (TKE), and dissipation rate complete the statistical analysis. Altogether, $41 \%$ of the flights are in weak, $14 \%$ in moderate, and $0.4 \%$ in strong mountain wave conditions according to thresholds for the measured vertical air velocity. As an exemplary case study, we compare measurements on 11 September 2019 to a high-resolution numerical weather prediction model. The case study provides a meaningful example of how data from soaring flights might be utilized for model validation on the mesoscale and within the troposphere.
\end{abstract}

KEYWORDS: Mountain waves; Turbulence; Wind; Aircraft observations

\section{Introduction}

Strong atmospheric flow over mountains excites gravity waves that propagate into the lee and up to high altitudes. The horizontal and vertical wavelengths, magnitude of vertical air velocity, and propagation characteristics of these waves depend on the upstream flow velocity and direction, the thermal stratification of the atmosphere, and the shape of the local orography (Lin 2010). Mountain wave research goes back to the early twentieth century (Smith 2019) and gained increasing relevance with the rise of aviation in general, as turbulence above and in the lee of mountains cause hazards for aircraft (e.g., Strauss et al. 2015; Sharman and Lane 2016; Bramberger et al. 2020; Wilms et al. 2020). The modeling of mountain waves is thus important for air traffic management and flight safety. On the other hand, the updrafts caused by mountain waves allow sailplanes to gain significant height in a short amount of time. Long-distance flights without engine support are possible when the flow crosses elongated mountain barriers like the Andes.

The first systematic investigation of mountain waves goes back to experiments with sailplanes (Küttner 1938). In the first, multi-institutional meteorological field campaign focusing on

\footnotetext{
Denotes content that is immediately available upon publication as open access.

Corresponding author: Norman Wildmann, norman.wildmann@ dlr.de
}

mountain waves - the Sierra Wave project in 1951-52 and 1955 (revisited by Grubišić and Lewis 2004)—sailplanes equipped with meteorological instrumentation played a leading role. The airborne measurements allowed us to gain a better physical understanding of mountain flows (Kuettner 1959) while at the same time important knowledge for aviation was collected and documented (Kuettner and Jenkins 1953).

Measurement systems for basic meteorological quantities (wind vector, temperature, humidity, and pressure) are usually a standard payload on the engine-powered research aircraft that allow us to probe the atmosphere in a systematic way as it was done in more recent big research programs and field campaigns in mountain meteorology research like Mesoscale Alpine Programme (MAP) (Bougeault et al. 2001), TerrainInduced Rotor Experiment (T-REX) (Grubišić et al. 2008), or Deep Propagating Gravity Wave Experiment (DEEPWAVE) (Fritts et al. 2016).

Beyond the research aircraft that were used in those campaigns, a variety of smaller aircraft have been used over the years for atmospheric research. Crawford and Dobosy (1992) developed a wind measurement flow probe called the "Best Aircraft Turbulence Probe" (BAT-probe) which could be installed on many small research aircraft (Hacker and Crawford 1999). Motor gliders such as the "Dimona" from MetAir (Neininger et al. 2001) were equipped with a variety of sensors, including flow probes for wind measurements, and proved to be very valuable tools for research in mountain meteorology (Rotach et al. 2004; Gohm et al. 2009). The advantage of small, engine-powered research aircraft is their flexible deployment and that they can reach low altitudes and valleys that are not 
easily accessible with larger research aircraft. Another type are ultralight aircraft that are versatile systems and have been equipped with turbulence probes (Metzger et al. 2011). They have many similar characteristics to sailplanes in their flight dynamics and the corresponding challenges for meteorological measurements. However, ultralight aircraft are not designed for soaring flights in the strong winds of the mountain waves in the Andes.

Developments in measurement technology at the beginning of the twenty-first century enabled small, microelectromechanical system (MEMS) sensors that could be used to build meteorological instrumentation that can even be carried by small unmanned aerial vehicles (UAVs) of only few kilograms. These are mainly deployed in boundary layer meteorology (van den Kroonenberg et al. 2008; Wildmann et al. 2015; Rautenberg et al. 2019). This advancement in measurement technology allows us to conduct thermodynamic measurements on very small, unmanned aircraft that are of similar quality as those of the larger research aircraft with the advantage of smaller flow disturbances by the measurement system itself. On the other hand, these small UAVs are limited in range and altitude by design, but also due to the difficult integration into air traffic management beyond visual line of sight of the operator (Neininger and Hacker 2011).

In this study, we designed, built, and deployed a measurement system similar to those for UAVs on a motor glider with the purpose of collecting high-resolution in situ wind and turbulence data during soaring flights in mountain waves. Such high-resolution measurements of three-dimensional wind and turbulence on an aircraft for soaring flights in mountain waves are rare. Comparable flights with a similar instrumentation were performed in 2006 by Hacker et al. (2007). Recent flights of the Perlan2 glider in 2019, which was developed within the Perlan project (Brahic 2012) included measurements with a turbulence probe in stratospheric mountain waves.

Unlike UAVs or large research aircraft, motor gliders or sailplanes are typically not automatically controlled by an autopilot to follow a predefined flight path with fixed airspeed. Soaring flights are characterized by ascents and descents with varying flight speeds, depending on the local vertical air velocities in the waves. Experience and knowledge about the physics of the wave flow is necessary to make the right decisions in flight and to find suitable waves for long-distance flights. The flights, therefore, include a range of different flight altitudes and airspeeds and include dynamic maneuvers. These flight conditions need to be considered in the design of the instrumentation as well as in the analysis and interpretation of the data. In this study, we present our measurement system that was developed for wind and turbulence measurements on a motor glider in mountain waves. Meaningful analyses of the data along irregular flight patterns are a difficult and not straightforward task that requires processing procedures optimized for these kinds of data.

In section 2 we introduce the experiment, including an overview of the research flights that were conducted in the lee of the Andes in 2019. Section 3 provides details about the aircraft and the measurement system. The calibration and analysis methods are described in section 4 . We focus on two topics that are particularly relevant for the soaring flight experiment. First, the wide range of airspeeds and the flow probe calibration with multiple calibration points is presented. Second, we investigate the possibility of disturbance of turbulence measurements in motor flight. In section 5 we present an overview of the flight conditions throughout all flights that were recorded by the measurement system in the Andes. A first analysis of the meteorological conditions during soaring flights in lee waves of the Andes was conducted. A case study is presented that gives an example of possible analyses of the soaring measurements through a comparison of the observations with numerical weather prediction model results that are interpolated onto the flight path.

\section{Campaign overview}

In the time between September 2019 and January 2020, a total number of 30 research flights were performed by the pilot Klaus Ohlmann with a Stemme S10-VT aircraft (see Table 1) in South America. Twelve of these flights were long-distance wave soaring flights with more than $5 \mathrm{~h}$ duration (denoted "soaring"), four were targeting to reach high altitudes (denoted "height"), five were shorter wave soaring flights in the vicinity of El Calafate (denoted "local waves"), and the rest are transit flights that include longer periods of motor flight (denoted "transit"). Figure 1 shows a map of all flight paths in Argentina and Chile. The official local time in Argentina is UTC minus $3 \mathrm{~h}$ although by its longitude, El Calafate would naturally be closer to UTC minus $5 \mathrm{~h}$. There is a focus of operation in the region around $\mathrm{El}$ Calafate where all flights were conducted in September 2019. This period of operation with the motor glider coincides with the Southern Hemisphere Transport, Dynamics, and Chemistry (SouthTRAC) campaign. The general idea of the soaring observations was to support the corresponding high-altitude measurements of High Altitude and Long Range Aircraft (HALO; Rapp et al. 2021) by in situ measurements closer to the sources of the mountain waves. September was chosen since the end of winter in the Southern Hemisphere is usually a season with strong wave activity from the troposphere to the stratosphere. Radiosondes were also launched irregularly from El Calafate on days of measurement flights, depending on the atmospheric conditions, but always at the full hour of 0000, 0300, 0600, 0900, 1200, 1500, 1800, or 2100 UTC. Flights later than October 2019 until January 2020 were undertaken farther north in the regions between Mendoza and Zapala.

\section{The measurement system and the numerical model}

\section{a. The aircraft}

In this campaign, a Stemme S10-VT aircraft (registration D-KKOP) was deployed that is owned and piloted by Klaus Ohlmann. The aircraft has a wingspan of $23 \mathrm{~m}$ and features a motor with retractable propeller. With the propeller retracted, the motor glider is essentially a sailplane. Figure 2 shows a schematic of the aircraft and a picture in flight. The Stemme S10-VT has previously been operated in scientific missions in the Andes as well as in the Himalaya within the Mountain Wave Project (Hacker et al. 2007; Lindemann et al. 2008; 
TABLE 1. Overview of flights. The flight that is described in section $5 \mathrm{c}(2)$ is marked with boldface font.

\begin{tabular}{|c|c|c|c|c|c|c|c|}
\hline Flight no. & Date & Start (UTC) & Start location & End (UTC) & End location & Flight time & Purpose \\
\hline 1 & 7 Sep 2019 & 2145 & El Calafate & 2238 & El Calafate & $0 \mathrm{~h} 53 \mathrm{~min}$ & Calibration \\
\hline 2 & 8 Sep 2019 & 1822 & El Calafate & 2155 & El Calafate & $3 \mathrm{~h} 33 \mathrm{~min}$ & Local waves \\
\hline 3 & 9 Sep 2019 & 1957 & El Calafate & 2204 & El Calafate & $2 \mathrm{~h} 7 \mathrm{~min}$ & Local waves \\
\hline 4 & 11 Sep 2019 & 1253 & El Calafate & 1554 & El Calafate & 3 h 1 min & Height \\
\hline 5 & 13 Sep 2019 & 1742 & El Calafate & 1952 & El Calafate & $2 \mathrm{~h} 10 \mathrm{~min}$ & Local waves \\
\hline 6 & 14 Sep 2019 & 1131 & El Calafate & 2111 & El Calafate & $9 \mathrm{~h} 40 \mathrm{~min}$ & Soaring \\
\hline 7 & 16 Sep 2019 & 1920 & El Calafate & 2240 & El Calafate & $3 \mathrm{~h} 20 \mathrm{~min}$ & Height \\
\hline 8 & 17 Sep 2019 & 1506 & El Calafate & 2118 & El Calafate & $6 \mathrm{~h} 12 \mathrm{~min}$ & Height \\
\hline 9 & 19 Sep 2019 & 1047 & El Calafate & 2140 & Malargue & $10 \mathrm{~h} 53 \mathrm{~min}$ & Soaring \\
\hline 10 & 20 Sep 2019 & 1608 & Malargue & 2126 & Bariloche & $5 \mathrm{~h} 18 \mathrm{~min}$ & Soaring \\
\hline 11 & 21 Sep 2019 & 1342 & Bariloche & 2238 & El Calafate & $8 \mathrm{~h} 56 \mathrm{~min}$ & Soaring \\
\hline 12 & 23 Sep 2019 & 1823 & El Calafate & 2143 & El Calafate & $3 \mathrm{~h} 20 \mathrm{~min}$ & Local waves \\
\hline 13 & 24 Sep 2019 & 1813 & El Calafate & 2238 & El Calafate & $4 \mathrm{~h} 25 \mathrm{~min}$ & Height \\
\hline 14 & 25 Sep 2019 & 1211 & El Calafate & 2218 & El Calafate & $10 \mathrm{~h} 7 \mathrm{~min}$ & Soaring \\
\hline 15 & 28 Sep 2019 & 1711 & El Calafate & 2209 & El Calafate & $4 \mathrm{~h} 58 \mathrm{~min}$ & Local waves \\
\hline 16 & 2 Oct 2019 & 1844 & Puerto Montt & 2143 & Conception & $2 \mathrm{~h} 59 \mathrm{~min}$ & Transit \\
\hline 17 & 3 Oct 2019 & 1341 & Conception & 1628 & Olmue/Limache & $2 \mathrm{~h} 47 \mathrm{~min}$ & Transit \\
\hline 18 & 26 Oct 2019 & 0940 & San Jose de Jachal & 2320 & Zapala & $13 \mathrm{~h} 40 \mathrm{~min}$ & Soaring \\
\hline 19 & 30 Oct 2019 & 1242 & Zapala & 1620 & Mendoza & $3 \mathrm{~h} 38 \mathrm{~min}$ & Transit \\
\hline 20 & 30 Oct 2019 & 1736 & Mendoza & 1912 & Santiago de Chile & $1 \mathrm{~h} 36 \mathrm{~min}$ & Transit \\
\hline 21 & 30 Oct 2019 & 2214 & Santiago de Chile & 2243 & Valparaiso & $0 \mathrm{~h} 29 \mathrm{~min}$ & Transit \\
\hline 22 & 15 Nov 2019 & 0920 & Zapala & 2320 & Zapala & $14 \mathrm{~h} 0 \mathrm{~min}$ & Soaring \\
\hline 23 & 17 Nov 2019 & 0942 & Zapala & 2344 & Zapala & $14 \mathrm{~h} 2 \mathrm{~min}$ & Soaring \\
\hline 24 & 25 Nov 2019 & 1646 & Zapala & 2308 & Zapala & $6 \mathrm{~h} 22 \mathrm{~min}$ & Soaring \\
\hline 25 & 11 Dec 2019 & 0851 & Zapala & 2233 & Zapala & $13 \mathrm{~h} 42 \mathrm{~min}$ & Soaring \\
\hline 26 & 13 Dec 2019 & 0845 & Zapala & 2340 & Mendoza & $14 \mathrm{~h} 55 \mathrm{~min}$ & Soaring \\
\hline 27 & 14 Dec 2019 & 1444 & Mendoza & 1619 & Santiago de Chile & $1 \mathrm{~h} 35 \mathrm{~min}$ & Transit \\
\hline 28 & 15 Dec 2019 & 1902 & Santiago de Chile & 1930 & Olmue & $0 \mathrm{~h} 28 \mathrm{~min}$ & Transit \\
\hline 29 & 2 Jan 2020 & 2103 & Santiago de Chile & 2237 & Mendoza & $1 \mathrm{~h} 34 \mathrm{~min}$ & Transit \\
\hline 30 & 9 Jan 2020 & 1648 & Malargue & 2232 & Zapala & $5 \mathrm{~h} 44 \mathrm{~min}$ & Soaring \\
\hline
\end{tabular}

Ledderhos et al. 2015) and has proven its value for flexible scientific measurements during high-altitude soaring flights. Among the 62 world records that Klaus Ohlmann holds, he won the Küttner prize for a straight glider flight to a goal more than $2000 \mathrm{~km}$ away in the year 2003 (Ohlmann 2011). This world record flight was started from El Calafate, the same base location chosen for the experiment described here. The unique experience and skills of Klaus Ohlmann were essential for the success of this campaign.

\section{b. Instrumentation}

The instrumentation consists of multiple components allowing the measurement of thermodynamic variables. Table 2 gives an overview of the components and their most relevant specifications. The wind measurement system consists of a five-hole probe for the measurement of the airflow vector and an inertial navigation system (INS) with global navigation satellite system (GNSS) for the measurement of the aircraft motion vector. Temperature and humidity are measured with a general purpose capacitive humidity sensor and semiconductor-based temperature sensor. In addition, a PT100 temperature sensor is included for temperatures below $-40^{\circ} \mathrm{C}$ and in case of failure of the first sensor. From the total air temperature measurement of these sensors, the static air temperature is calculated using a recovery factor of $r_{f}=1$. All temperatures that are shown in the analyses are static air temperature. An absolute pressure transducer is calibrated for barometric pressure to allow measurements of air pressure up to high altitudes at a resolution of $0.05 \mathrm{hPa}$.

The INS-GNSS system of type SBG Systems Ellipse2-D was chosen for this project because of its applicability in airborne systems, featuring optimized internal Kalman filter motion profiles for this purpose (Guinamard 2018). The possibility to install a dual-antenna GNSS configuration especially for improved heading accuracy was another important criteria. As can be seen in Fig. 2, the antennas were installed along the spanwise direction with a baseline of $4.38 \mathrm{~m}$. A very good rated angular accuracy of $0.2^{\circ}$ heading is achievable with this configuration. The flow probe is a straight boom configuration manufactured by the company Vectoflow $\mathrm{GmbH}$ with a round tip with five holes and a static pressure port ring. Its calibration is described in more detail in section 4. In contrast to wind measurements that are based on flow probes measuring only airspeed as for example previously used on the Stemme S10VT by Lindemann et al. (2008), our system allows the direct measurements of the flow vector, and in combination with the inertial measurements, the three-dimensional wind vector with a sampling rate of $100 \mathrm{~Hz}$. Due to pneumatic damping of the tubing of the flow probe, we retrieve data with a rate of $20 \mathrm{~Hz}$ only, to be able to analyze turbulence data with a temporal resolution of $10 \mathrm{~Hz}$ that is not affected significantly by any low-pass filtering effects in the system. Table 2 gives the rated accuracy of all sensors. An estimation of actual 


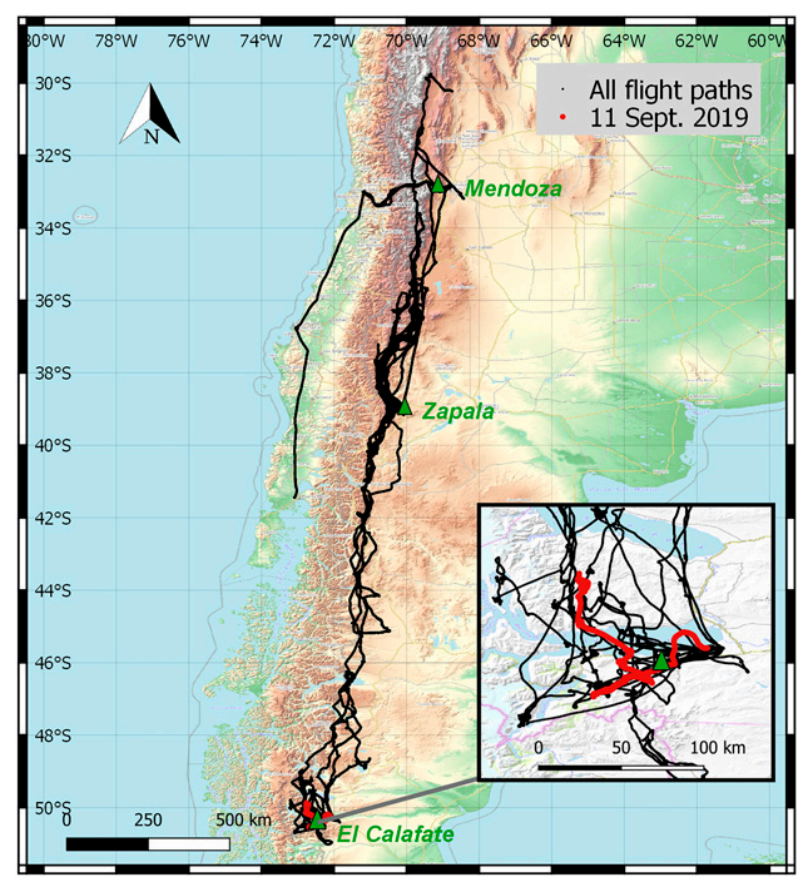

FIG. 1. Map of all flight paths over Argentina and Chile between September 2019 and January 2020. The flight on 11 Sep 2019 is marked with red color. COpenStreetMap-Contributors, SRTM; map: @OpenTopoMap (CC-BY-SA).

uncertainties of the measurements in flight is given in section $4 \mathrm{c}$. Figure 3 shows a schematic of the system with its components.

\section{c. Met Office Unified Model}

In a case study, the measurements are compared with output from the Met Office Unified Model (MetUM), in order to assess the accuracy of the modeled wave field. The MetUM is used across resolutions and time scales for many purposes, including investigation of surface drag (van Niekerk et al. 2016) and for mountain wave process evaluation, but is also used operationally for high resolution regional numerical weather prediction and climate projections (Vosper et al. 2020). For this study, a limited area domain with a horizontal resolution of $1 \mathrm{~km}$ and 118 vertical levels up to $78 \mathrm{~km}$ is used [see Bush et al. (2020) for details of regional configuration]. The vertical resolution is about $10 \mathrm{~m}$ near the surface, then progressively increases to $500 \mathrm{~m}$ up to $20 \mathrm{~km}$ AGL, after which it increases almost linearly up to $3 \mathrm{~km}$ at the model top. The digital elevation model used is the GLOBE30 data at a resolution of $1 \mathrm{~km}$. The domain covers approximately $65^{\circ}-44^{\circ} \mathrm{S}, 84^{\circ}-$ $55^{\circ} \mathrm{W}$ and uses a rotated-pole latitude-longitude grid with a gridpoint resolution of $0.01^{\circ}$. Lateral boundary conditions are generated from the Met Office operational global deterministic forecasts that are at a resolution of approximately $9 \mathrm{~km}$, and are updated hourly. Both the limited area domain and the global model are initialized from Met Office operational analyses. The limited area domain is reinitialized at 6-hourly intervals and run for $48 \mathrm{~h}$ for each day between 5 September and 25 November 2019. The model uses a zero-mass-flux upper and lower boundary condition, meaning that time derivate of the terrain following vertical coordinate is zero there. Damping of the vertical winds is also applied above a height of about $30 \mathrm{~km}$.

\section{Methods}

\section{a. Flow probe calibration}

A central part of the wind measurement system is the fivehole flow probe. It measures the flow angles through differential pressures at the hemispherical probe tip. The angle of attack $\alpha$, angle of sideslip $\beta$, and the true airspeed $v_{\text {tas }}$ are

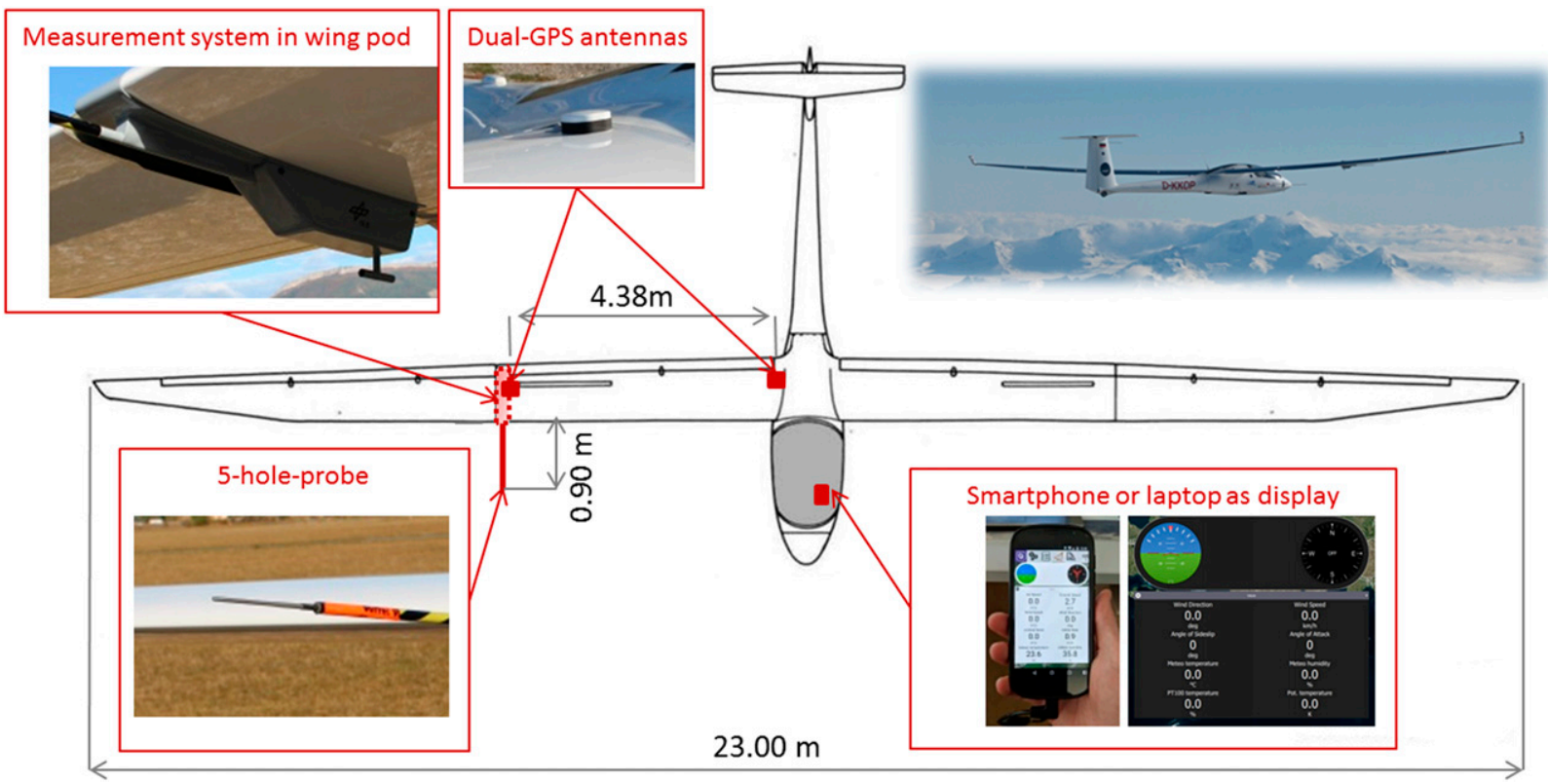

FIG. 2. Schematic of the Stemme S10-VT aircraft. Red markers indicate the location of parts of the wind measurement system. 
TABLE 2. Measurement system components and characteristics.

\begin{tabular}{ll}
\hline \hline Five-hole probe & Vectoflow GmbH, straight configuration \\
Probe tip diameter & $\varnothing=5 \mathrm{~mm}$ \\
Probe length & $L=160 \mathrm{~mm}$ \\
Pressure scanner & SVM-PSC5-CAN \\
Differential pressure transducer range & $\pm 25 \mathrm{mb}$ \\
Absolute pressure transducer & 0 to $1100 \mathrm{mb}$ \\
Inertial navigation system and GPS & SBG Systems Ellipse2-D \\
Rated velocity accuracy & $0.03 \mathrm{~m} \mathrm{~s}-1$ \\
Rated angle accuracy & $0.1^{\circ}$ (roll/pitch), $0.2^{\circ}$ (heading) \\
GPS receiver & Dual antenna, single frequency \\
GPS antenna baseline & $\approx 4 \mathrm{~m}$ \\
Temperature and humidity sensor & HYT 271 \\
Temperature range & $-40^{\circ}$ to $125^{\circ} \mathrm{C}$ \\
Temperature accuracy & $\pm 0.2 \mathrm{~K}$ \\
Temperature, rated response time & $\tau_{63}<5 \mathrm{~s}$ \\
Humidity range & $0 \%$ to $100 \% \mathrm{RH}$ \\
Humidity accuracy & $\pm 1 \% \mathrm{RH}$ \\
Humidity, rated response time & $\tau_{63}<5 \mathrm{~s}$ \\
Secondary temperature sensor & PT100 \\
Temperature range & $-100^{\circ}$ to $400^{\circ} \mathrm{C}$ \\
Datalogger and telemetry & Pixhawk, PX 4 \\
Housing & GFL UG custom design \\
Length of system, including pole & $\approx 1.5 \mathrm{~m}$ \\
Dimensions & $350 \mathrm{~mm} \times 87 \mathrm{~mm} \times 70 \mathrm{~mm}$ \\
Weight & $<2 \mathrm{~kg}$ \\
\hline & \\
\hline
\end{tabular}

calculated from the differential pressures through calibration coefficients that are determined in a wind tunnel with welldefined flow conditions. The calibration method we use here is described for a single flow velocity in Wildmann et al. (2014). A calibration for a measurement range of $\pm 20^{\circ}$ for angle of attack $\alpha$ and sideslip $\beta$ is performed, which covers all typical flight conditions. Since the motor glider aircraft can go through a wide range of flight speeds with different Reynolds numbers and thus different flow characteristics at the probe tip, we decided that multiple calibrations of the probe should be performed. Metzger et al. (2011) calibrated their flow probe used on an ultralight aircraft with increments of $2 \mathrm{~m} \mathrm{~s}^{-1}$, but for a much smaller range of airspeeds than is required in our case. After consulting the manufacturer Vectoflow, we decided to calibrate the flow probe for this system at four distinct flow velocities (see Fig. 4). The flow angles and airspeed are linearly interpolated between the two closest calibration points after a first guess of the true airspeed from the pitot static pressure difference in flight. Figure 4 shows the statistics of flight speeds in relation to the calibration points. The calibration point at the lowest speed is outside the range of speeds that can be reached with the Stemme aircraft, but is still valuable, since flow characteristics change significantly with such low airspeeds and the system can potentially also be installed on other aircraft.

\section{EFFECTS OF CALIBRATION INTERPOLATION}

To evaluate the accuracy of multiple calibration regimes and the interpolation between them for the five-hole probe measurements, we analyze all flights and calculate the differences of angle of attack $\Delta \alpha$, angle of sideslip $\Delta \beta$ and dynamic pressure $\Delta q$ between single calibration coefficient results (calib_i) and the interpolated results.
When comparing the interpolated results to single calibration coefficient results we find that the deviation increases with increasing difference of measured Mach number to calibration Mach number. Figure 5 shows the result of the comparison. An error $\Delta \alpha$ on the order of $1^{\circ}$ can yield vertical wind speed error of approximately $0.4 \mathrm{~m} \mathrm{~s}^{-1}$ and the same value in $\Delta \beta$ can yield up to $1.25 \mathrm{~m} \mathrm{~s}^{-1}$ error in the horizontal components according to van den Kroonenberg et al. (2008). A single calibration of the probe at 0.125 Mach would yield errors of $0.3 \mathrm{~m} \mathrm{~s}^{-1}$ and thus significant contributions to vertical wind speed uncertainty. The errors on the order of $1 \mathrm{~Pa}$ in $\Delta q$ are however not significant for wind speed measurements. Since the dependence of the calibration on airspeed between the calibration points is nearly linear, we expect that the potential error is mostly eliminated by a linear interpolation between the calibration points.

\section{b. Wind vector calculation}

The meteorological wind vector $\mathbf{v}$ is calculated from measurements of the INS-GNSS and the flow probe. Orientation angles of the aircraft (roll $\varphi$, pitch $\theta$ and yaw $\psi$ ), ground speed

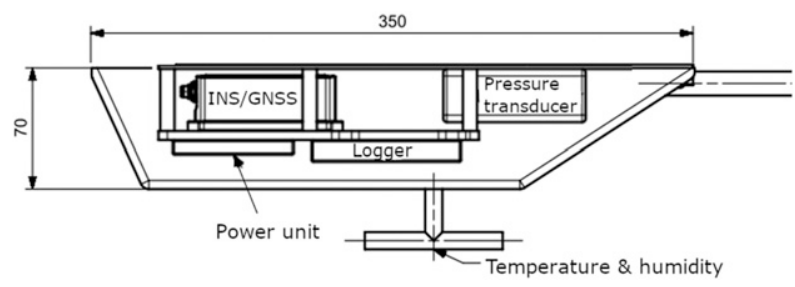

FIG. 3. Technical drawing of the housing of the measurement system and the included components. 


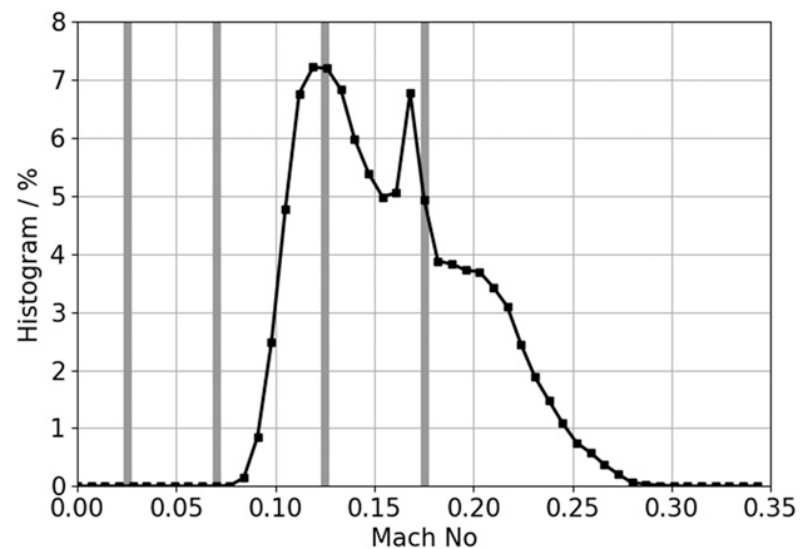

FIG. 4. Histogram of all flight speeds of the Stemme aircraft recorded in the experiment with a bin width of $2 \mathrm{~m} \mathrm{~s}^{-1}$. The calibration points of the five-hole probe are indicated by the vertical bars. The histogram is normalized by the length of the dataset.

$\mathbf{v}_{g}$ and the airspeed vector $\mathbf{v}_{a}$ are used to obtain the threedimensional wind vector $\mathbf{v}$ :

$$
\mathbf{v}=\mathbf{v}_{g}+\mathbf{M} \mathbf{v}_{a}
$$

where $\mathbf{M}$ is the rotation matrix from body coordinates of the aircraft to the geodetic coordinates composed of the orientation angles (Wildmann et al. 2014).

A calibration maneuver over Lago Argentino was performed on 7 September 2019 on a calm day for in-flight calibration of angle misalignments and true airspeed correction following the general idea of Lenschow maneuvers (Lenschow et al. 1986). The maneuver consists of straight flight legs of $5-8 \mathrm{~km}$ in north-south, south-north, east-west, and west-east direction at an altitude between 800 and $1000 \mathrm{~m}$ and a true airspeed of $\approx 45 \mathrm{~m} \mathrm{~s}^{-1}$. The difference to a presumably constant wind vector with zero vertical air velocity as measured in different flight directions is minimized through the introduction of yaw and pitch offsets and a true airspeed factor. We found a pitch misalignment of $\Delta \theta=2.15^{\circ}$, a yaw misalignment of $\Delta \psi=0.96^{\circ}$ and a true airspeed correction factor of $f_{\operatorname{tas}}=1.1$. Since no changes were made on the measurement system throughout the campaign, we use the calibration coefficients of this flight for all other flights.

\section{1) Turbulence meAsurements}

By design, the measurement system allows us to measure turbulent fluctuations of the three-dimensional wind vector up to $100 \mathrm{~Hz}$. Due to the length of the flow probe tubing of $\approx 1 \mathrm{~m}$, pneumatic damping will significantly affect the small-scale fluctuations (Wildmann et al. 2014) and we therefore only analyze data up to $10 \mathrm{~Hz}$. Assuming that the largest energycontaining turbulent eddies are larger than $100 \mathrm{~m}$ and flight speeds are below $100 \mathrm{~m} \mathrm{~s}^{-1}$ the data include a significant part of the inertial subrange of turbulence and thus allow retrieving turbulent kinetic energy (TKE) dissipation rate $\varepsilon$ from secondorder structure function fits. That means that the theoretical structure function [Eq. (3)] is fit to the measured structure function [Eq. (2)] in a range $\tau_{\min }$ to $\tau_{\max }$, which is assumed to follow the Kolmogorov slope 2/3 (Kolmogorov 1991) in the inertial subrange of locally isotropic turbulence:

$$
\begin{aligned}
D_{m}(\tau) & =\overline{[U(t)-U(t+\tau)]^{2}}, \\
D_{k}(\tau) & =C_{k} \varepsilon^{2 / 3}(\bar{U} \tau)^{2 / 3},
\end{aligned}
$$

where $D_{m}(\tau)$ is the measured structure function, $D_{k}(\tau)$ the theoretical structure function, $C_{k} \approx 2$ is the Kolmogorov constant, $U$ is the horizontal wind in the main wind direction, and bars indicate the average. We choose a constant $\tau_{\min }=0.25 \mathrm{~s}$ and $\tau_{\max }=1 \mathrm{~s}$ for all flights. For the fastest recorded airspeed this still yields maximum separation distances below $100 \mathrm{~m}$.

Additionally, TKE is calculated as half of the sum of the variances $\sigma^{2}$ of the three wind components $u, v$, and $w$ :

$$
\mathrm{TKE}=\frac{1}{2}\left(\sigma_{u}^{2}+\sigma_{v}^{2}+\sigma_{w}^{2}\right) .
$$

Before calculating the variances, linear trends are removed from the data, which can occur in sheared flow during ascending or descending flight segments. We calculate turbulence in moving
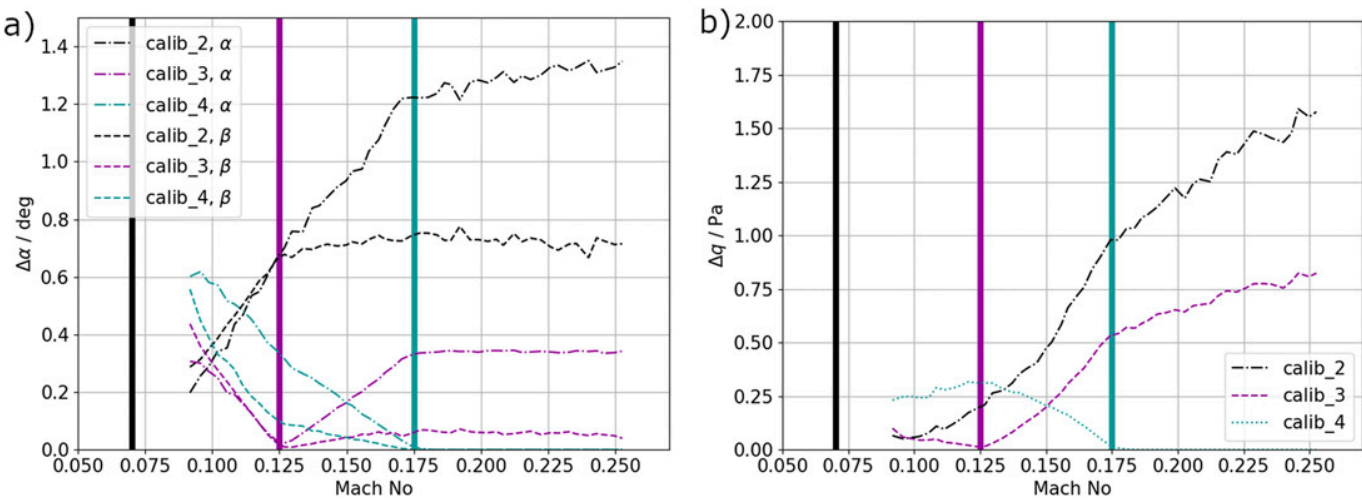

FIG. 5. Difference between single calibration regime calculation and interpolated result for (a) $\alpha$ and $\beta$ and (b) $q$. Thick vertical bars indicate the Mach number of the single calibrations corresponding to the grayscale of the curves. Data are averaged in bins of $1 \mathrm{~m} \mathrm{~s}^{-1}$. 

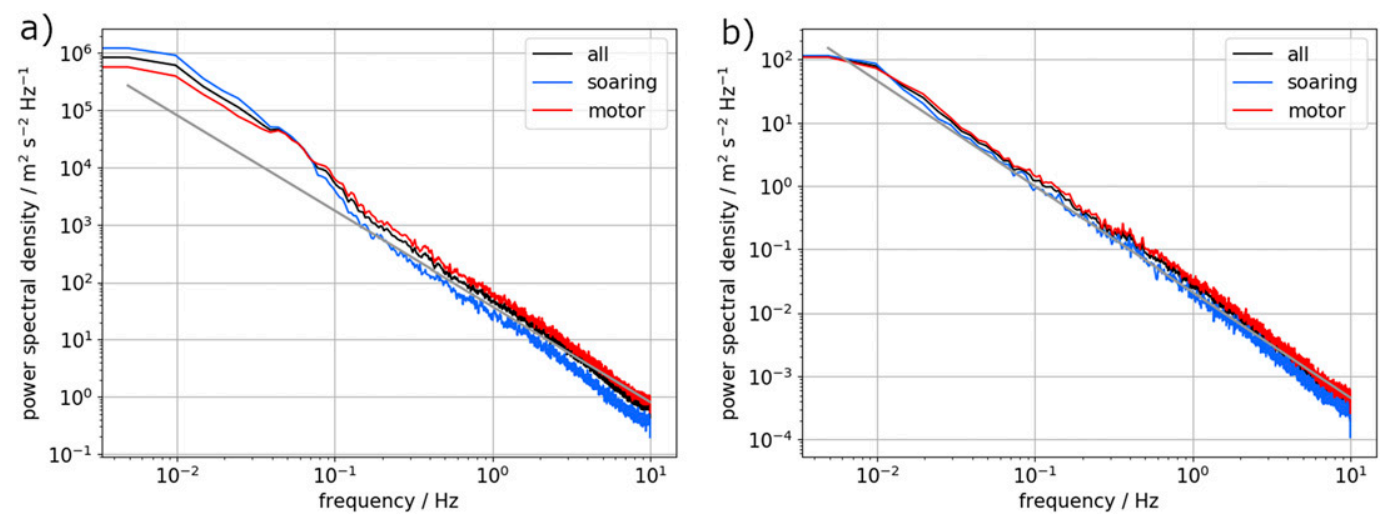

FIG. 6. Power spectra of dynamic pressure at (a) the five-hole probe tip hole and (b) horizontal wind speed. Shown are averages of all flight periods in motor flight (red), soaring flight (blue), and the average of all (black).

windows of $50 \mathrm{~s}$ width, which corresponds to a flight leg length of $2.5 \mathrm{~km}$ on average. We assume that the largest turbulent eddies are never larger than this. It has to be noted that for the dynamic flights, which feature changes in altitude and airspeed, the TKE calculated with this method can differ from the TKE as it would be measured at single heights and points in space. Nevertheless, the TKE results provide a measure of turbulence conditions in a statistical sense if regarded over all flights.

\section{2) FLOW DISTURBANCE IN MOTOR FLIGHT}

Although the goal of the experiment was to measure within mountain waves during soaring phases of the flights, it is still interesting and important to check if significant disturbance of the airflow around the flow probe can be detected during motor flight, especially since we compare the results of soaring flights to motor flight in this study. To answer this question we look at the averaged variance spectra of tip-hole pressure at the flow probe and the spectra of calculated horizontal wind speed (see Fig. 6).

In comparison to the spectra from soaring flights, the atmosphere during motor flights contains more turbulence and thus leads to higher spectral energy. Large parts of the soaring flights in the ascending branches of the mountain waves were conducted in essentially laminar flows, with very low turbulence. No peak or deformation of the spectra can be detected in the motor flights, indicating that the motor backwash is not captured at the location of the probe tip and vibrations do not cause a signal in these quantities. The small change in the slope of the spectra above $2 \mathrm{~Hz}$ can be attributed to the start of pneumatic damping of the probe tubing and is common for all flight conditions.

\section{c. Accuracy estimation}

Estimation of the accuracy of the measured data in flight is challenging, as many parameters are involved in the wind calculation and the accuracy of the sensors, especially the INS-GNSS system, which is essential for the wind measurement, depends on the dynamics of the flight and the performance of the Kalman filter to estimate the orientation angles. Nevertheless, an estimate can be made based on the rated sensor accuracies and knowledge about the calibration uncertainties. Van den Kroonenberg et al. (2008) calculated wind component uncertainties from sensor uncertainties and found errors on the order of $0.5 \mathrm{~m} \mathrm{~s}^{-1}$ for all three wind components without consideration of in-flight calibration errors. The sensor uncertainties for the orientation angles in van den Kroonenberg et al. (2008) were one order of magnitude higher than the rated accuracies of the INS-GNSS system used in this study (see Table 2), which can be attributed to the development in sensor technology and Kalman filtering in the last 15 years as well as the aiding of a dualantenna GNSS system. Wind tunnel calibration accuracy of the flow angles yields an uncertainty of $\approx 0.2^{\circ}$ for the flow angles and $0.02 \mathrm{~m} \mathrm{~s}^{-1}$ for airspeed. The linear interpolation between multiple calibration points maintains this accuracy over the whole range of airspeeds. We expect the largest uncertainties to occur due to uncertainties in the estimation of misalignments between sensors and aerodynamic effects like wing upwash that can only be calibrated in flight. A very comprehensive study of uncertainties was done by Metzger et al. (2011) for the flow probe on an ultralight aircraft and uncertainties of the in-flight calibration on the order of $0.3^{\circ}$ for flow angles and $0.3 \mathrm{~m} \mathrm{~s}^{-1}$ for airspeed were found. Without an independent reference, we cannot determine the uncertainty of our in-flight calibration precisely, but we estimate it to be on the order of $0.5^{\circ}$ and $0.5 \mathrm{~m} \mathrm{~s}^{-1}$. Using these values as the input for a linear error propagation through the wind vector calculation and applying it to a typical flight, average uncertainties for the wind components of $\sigma_{u}=0.57 \mathrm{~m} \mathrm{~s}^{-1}$, $\sigma_{v}=0.54 \mathrm{~m} \mathrm{~s}^{-1}$, and $\sigma_{w}=0.44 \mathrm{~m} \mathrm{~s}^{-1}$ are calculated.

Rather large uncertainties were observed for temperature measurements with our system, which could likely be caused by insufficient airflow to the sensor and thus a heating by the housing through heat conduction of the internal electronic components. We found the bias to radiosondes to be on the order of $2 \mathrm{~K}$, but especially in very low temperatures, this can be even higher. To minimize the error, the observed average bias to radiosonde measurements of $2 \mathrm{~K}$ was subtracted from the measured values in postprocessing. In worst case, a temperature error of $5 \mathrm{~K}$ at a true airspeed of $50 \mathrm{~m} \mathrm{~s}^{-1}$ at $300 \mathrm{hPa}$ 

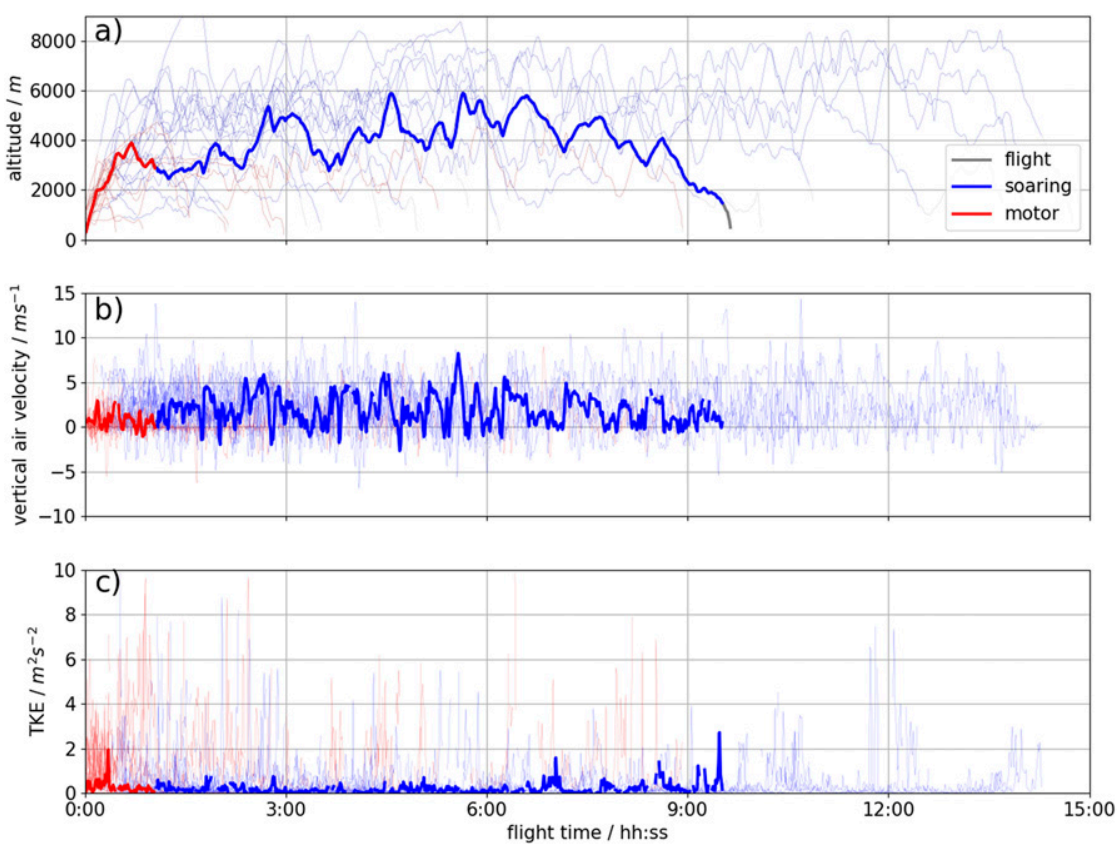

FIG. 7. Time series of (a) altitude, (b) vertical air velocity, and (c) TKE for all measurement flights. Periods of motor flight are colored red, and periods of soaring flight are colored blue. The flight on 14 Sep 2019 is highlighted in thick lines as an example of a long-distance wave soaring flight.

and $-40^{\circ} \mathrm{C}$ would yield an additional error of $0.5 \mathrm{~m} \mathrm{~s}^{-1}$ to the wind measurement. In average flight conditions in soaring flights, the error is only $0.15 \mathrm{~m} \mathrm{~s}^{-1}$.

Concluding the accuracy estimation, we believe that the system will provide data with an uncertainty on the order of $0.5 \mathrm{~m} \mathrm{~s}^{-1}$ in all wind components during most of the flights and that the error can increase to $1 \mathrm{~m} \mathrm{~s}^{-1}$ in high altitude and low temperature flights. These uncertainties are slightly higher than what is estimated as the overall wind measurement uncertainty by Crawford and Dobosy (1992) $\left(\sigma_{u, v}=0.25 \mathrm{~m} \mathrm{~s}^{-1}, \sigma_{w}=0.5 \mathrm{~m} \mathrm{~s}^{-1}\right)$, Metzger et al. (2011) $\left(\sigma_{u, v}=0.4 \mathrm{~m} \mathrm{~s}^{-1}, \sigma_{w}=0.3 \mathrm{~m} \mathrm{~s}^{-1}\right)$, and Mallaun et al. (2015) $\left(\sigma_{u, v}=0.3 \mathrm{~m} \mathrm{~s}^{-1}, \sigma_{w}=0.25 \mathrm{~m} \mathrm{~s}^{-1}\right)$ for their systems.

\section{Results}

\section{a. Flight description}

The analyzed flights of the measurement campaign in the Andes are diverse and vary in flight time, flight altitude, and location. Figure 1 shows all the flight paths along the Andes mountain range. Table 1 gives the overview of flight parameters. To understand the dynamics of the flights better, Fig. 7 shows the time series of altitude of all flights with respect to the takeoff time. The Stemme S10-VT, unlike a pure sailplane, can take off using the propulsion of its retractable propeller. Takeoff and first ascent is thus a phase of motor flight, until considerable lift is detected and the propeller is retracted. Often, the small mountain range southwest of El Calafate is used to get the first lift and the wave of one of the mountains farther west and closer to the main crest of the Andes is used to enter wave soaring. In most flights, the aircraft remains in soaring flight with alternating phases of ascent and descent. For the analysis of the flights, we separate the times of flight with motor support from soaring flight periods. The motor flight dataset thus includes the ascents after takeoff and early periods of the flights. Transit flights with motor support are also included in this subset of data. The soaring datasets includes the flight periods without motor support whereas the data of the final approach for landing were excluded. Figure $7 \mathrm{~b}$ shows the vertical air velocities during the flights and it is obvious that in the soaring phase, mostly vertical wind components are found that range between 0 and $5 \mathrm{~m} \mathrm{~s}^{-1}$ with some short periods of higher or lower vertical winds. Correspondingly, TKE (Fig. 7c) is found to be mostly low in the soaring flights with some short outbursts of higher turbulence. In the highlighted example flight of 14 September 2019, these phases of higher turbulence can be connected to descending flight phases, when the laminar flow of the ascending branch of the wave is presumably left. The statistics of all flights will be analyzed in the next section.

\section{b. Flight statistics}

To document the flight conditions throughout the measurement flights, we show histograms of altitude, true airspeed, horizontal wind and wind direction in Fig. 8. The histograms show the result of the complete flights in comparison to flight periods of only wave soaring and flight periods of only motor flight. The comparison of wave soaring periods to motor flights illustrates the specific conditions for wave soaring. It is obvious that only with westerly winds, wave soaring is possible in the lee of the Andes. The observed horizontal wind speeds in the 

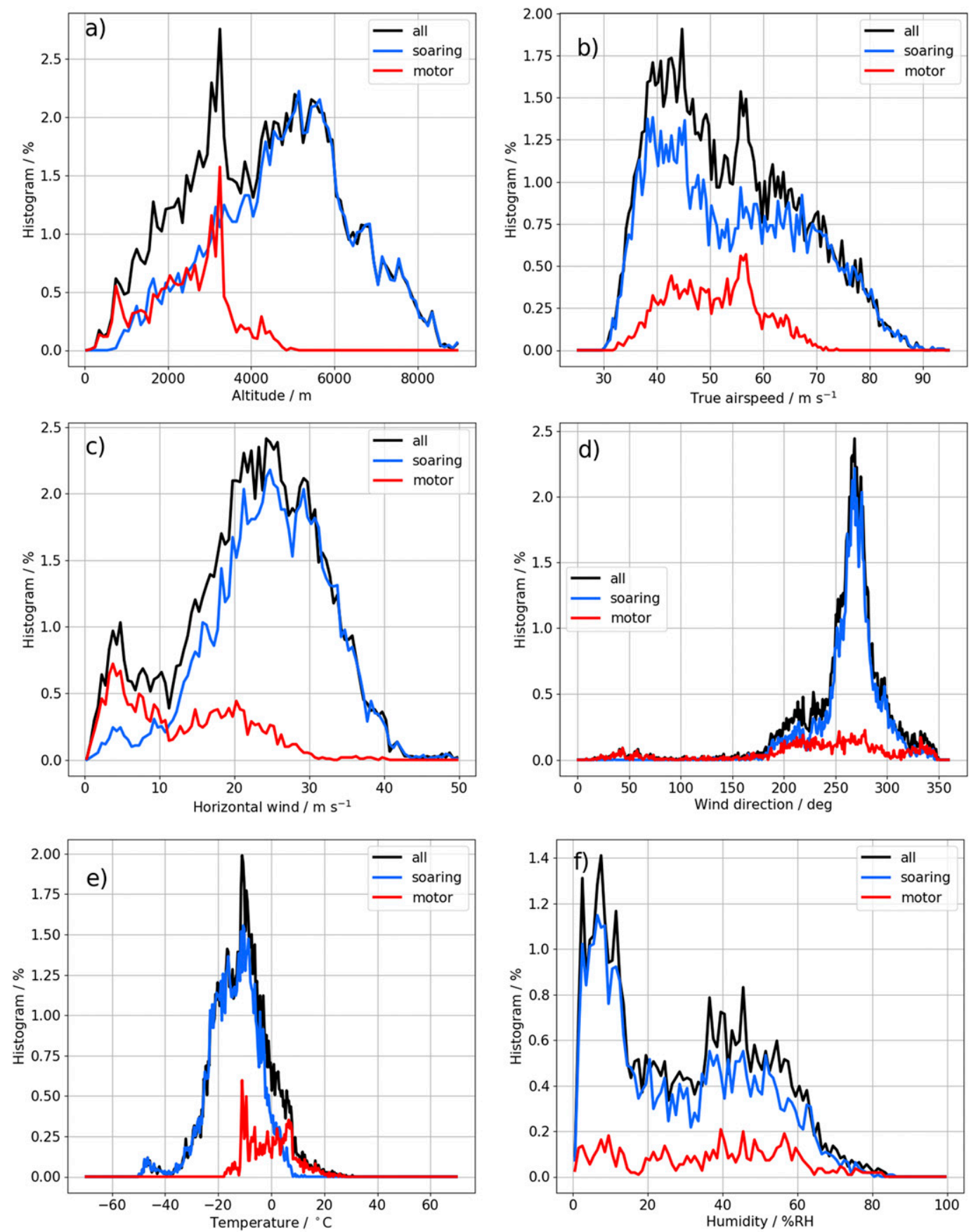

FIG. 8. Histograms of (a) altitude, (b) airspeed, (c) horizontal wind speed, (d) wind direction, (e) temperature, and (f) relative humidity for all measurement flights. The histogram values are normalized by the length of the dataset.

ascending branches of the mountain lee waves are predominantly larger than $10 \mathrm{~m} \mathrm{~s}^{-1}$ suggesting significantly stronger upstream winds to trigger waves with enough vertical air motion to allow soaring. While the cruising altitude of the Stemme aircraft in motor flight was predominantly at flight level 100 (FL $100 \approx 3000 \mathrm{~m}$ ), the majority of wave soaring flight reach up to FL $195(\approx 6000 \mathrm{~m})$. True airspeed varies between 30 and
$90 \mathrm{~m} \mathrm{~s}^{-1}$. Very low temperatures for glider flights below $-40^{\circ} \mathrm{C}$ were occasionally measured at the highest altitudes in the dataset. Moreover, it is obvious that the flights are all done in regions with comparatively low relative humidity below $80 \%$, as flying through clouds is potentially dangerous and prohibited for the type of aircraft used in this study. In a majority of the soaring flights the relative humidity is even below $20 \%$. 


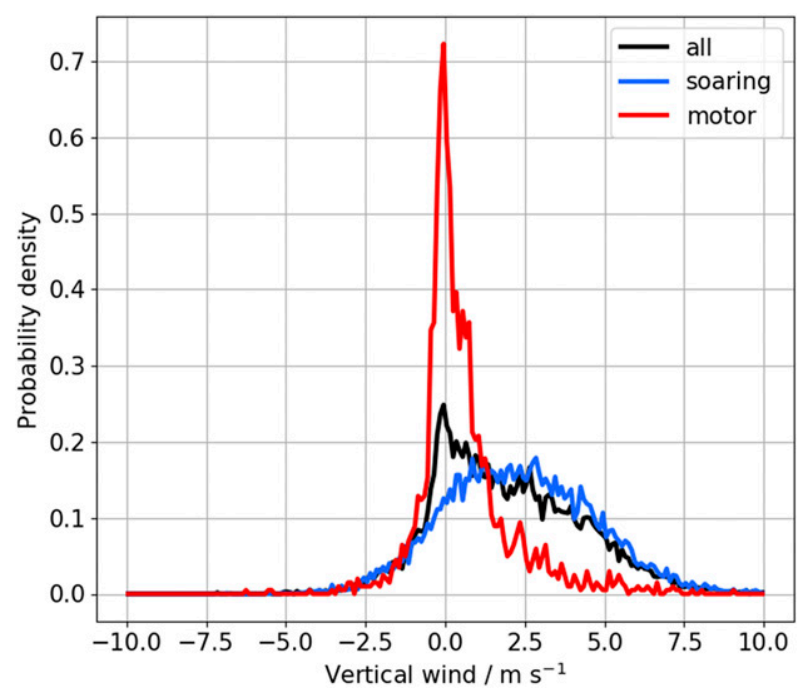

FIG. 9. Probability density function of vertical wind measurements for all flights.

The temperature and humidity readings of the measurement system in the wing pod have to be analyzed with some care as described in section 4c.

\section{c. Mountain wave measurements}

\section{1) Statistics}

The statistics of all flights allow us to evaluate some of the meteorological conditions observed during the measurements in mountain lee waves. Figure 9 shows the probability density function of vertical air velocity for all measurement flights. Again, we discriminate only wave soaring flight periods against motor flight periods. All the data that are used for the following analysis are calculated with a moving average of the same time window as it was introduced for turbulence measurements, i.e., $50 \mathrm{~s}$. Here it shows that during the motor flight periods without significant wave activity, the maximum is at vertical velocity equal to zero. This is what we expect by sampling the atmosphere randomly. This result increases confidence in the inflight calibration of the wind measurement (particularly the pitch offset). For $92.5 \%$ of the soaring flight data, the horizontal wind speed was $>10 \mathrm{~ms}^{-1}$, which suggests that the presented soaring statistics are indeed representative for wave soaring conditions rather than thermal soaring conditions. The vertical air velocities during all wave soaring flights are centered with an almost Gaussian distribution around the aircraft's average sink rate of $\approx 2.35 \mathrm{~m} \mathrm{~s}^{-1}$ (see more information in the appendix). Maximum vertical velocities of more than $10 \mathrm{~m} \mathrm{~s}^{-1}$ were occasionally recorded with a low rate of occurrence. Holmboe and Klieforth (1957) and Grubišić and Lewis (2004) categorized the waves in the Sierra Wave project into the classes "strong" $\left(9<|w|<18 \mathrm{~m} \mathrm{~s}^{-1}\right)$, "moderate" $(4.5<$ $\left.|w|<9 \mathrm{~m} \mathrm{~s}^{-1}\right)$, and "weak" $\left(1.5<|w|<4.5 \mathrm{~m} \mathrm{~s}^{-1}\right)$. Using these categories, we find that within the soaring flight parts of this experiment $40.6 \%$ are in weak, $14.1 \%$ in moderate and $0.4 \%$ in strong wave conditions. All other parts of the flights with vertical wind speeds $|w|<1.5 \mathrm{~m} \mathrm{~s}^{-1}$ are not considered in this categorization and presumable outside of significant wave activity.

The laminar flow in the mountain waves is documented by turbulence measurements of the glider. Figure 10 shows probability density functions of measured TKE and its dissipation rate $\varepsilon$. It shows that very low turbulence is found in the waves, especially in comparison to the motor flights. Values of $\varepsilon$ as low as $10^{-6} \mathrm{~m}^{2} \mathrm{~s}^{-3}$ are recorded, a value that can also be considered as the detection limit of the flow probe, meaning that it is likely that actual dissipation rates are even lower than the estimated ones. The parts with higher turbulence are attributed to flight periods when the aircraft enters or leaves the waves. Severe turbulence in breaking waves or rotors was not targeted in this experiment.

\section{2) CAse study, 11 September 2019}

To evaluate the data quality and the potential of soaring measurements for model validation in more detail, we investigate a case study of a single flight on 11 September 2019. Dörnbrack et al. (2020) investigated the occurrence of a rare mountain wave-induced mother-of-pearl cloud over El Calafate on this day. The predicted strong mountain waves between Lago Argentino and Lago Viedma were targeted by Klaus Ohlmann with the goal to reach high altitudes up to the tropopause, by soaring on the local waves. In Fig. 1, the flight path of 11 September 2019 is marked red. Figure 11 shows the vertical air velocity from MetUM at four levels (2000, 4000, 6000, and $8000 \mathrm{~m}$ ), overlaid with the flight track of D-KKOP, and the observed vertical air velocity in the same color scale. The model predicts strong wave lift regions in the vicinity of the flight path. For the location of highest vertical velocities and fastest climb rates of the aircraft close to $-50^{\circ}$ latitude, $-72.8^{\circ}$ longitude, it appears that the actual wave lift occurred farther east than the predicted wave lift in the model output. To investigate more closely if only a shift of phase in the model occurs and magnitudes are captured correctly, we shifted the flight track of D-KKOP by $0.05^{\circ}(\approx 4 \mathrm{~km})$ to the west as shown by the gray line in the figure. The horizontal wavelength of the mountain wave at $49.95^{\circ} \mathrm{S}$ close to the flight path is $21.5 \mathrm{~km}$ in the model.

For both, the true flight track and the shifted flight track, we interpolated the model results on the time and location of the aircraft. The results for the three wind components and temperature are given in Figs. 12a-d). Figure 12d additionally gives the flight altitude. The recorded data end at a flight altitude of $8000 \mathrm{~m}$ because in this first low temperature flight, the datalogging stopped likely due to a failure of the SD card at low temperatures. The problem was resolved for later flights. Gaps in the model data between 1315 and 1400 UTC are because the flight altitude is below the lowest model level in these cases. A comparison of MetUM-model orography to the TanDEM-X $90 \mathrm{~m}$ resolution digital elevation model (Rizzoli et al. 2017) is shown in Fig. 12e and illustrates the level of smoothing in the model. The plots of the wind components show that the magnitude of increase of $u$-wind component agrees well between measurement and model, which results in a better correlation (Fig. 12f) compared to the other two wind components (Figs. 12g,h). The generally weaker $v$ component shows some 

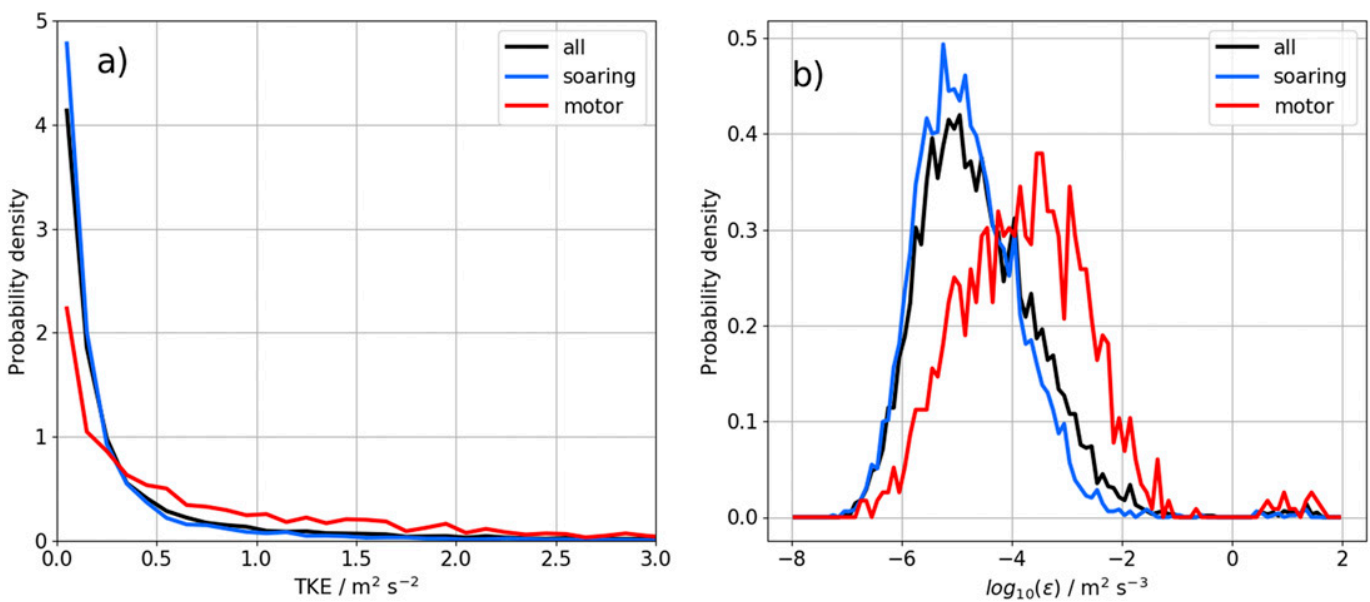

FIG. 10. Probability density functions of (a) TKE and (b) $\varepsilon$ for all measurement flights.

larger deviations and is underestimated by the model. The magnitude of the vertical wind component is also higher in the aircraft measurements compared the model output, especially in the phases of rapid ascent of the glider. The temperature comparison shows good agreement and correlation between the measurements and the model except for the small offset in the final ascent (Figs. 11d,i). The period of 1425-1440 UTC corresponds to the area close to $50.5^{\circ} \mathrm{S}, 72.4^{\circ} \mathrm{W}$. The glider gains almost $1.5 \mathrm{~km}$ altitude in these $15 \mathrm{~min}$ with a maximum of $7 \mathrm{~m} \mathrm{~s}^{-1}$ vertical velocity. At that time in the interpolated model data, we do not find any significant wave lift, but we see that the difference between model orography and digital elevation
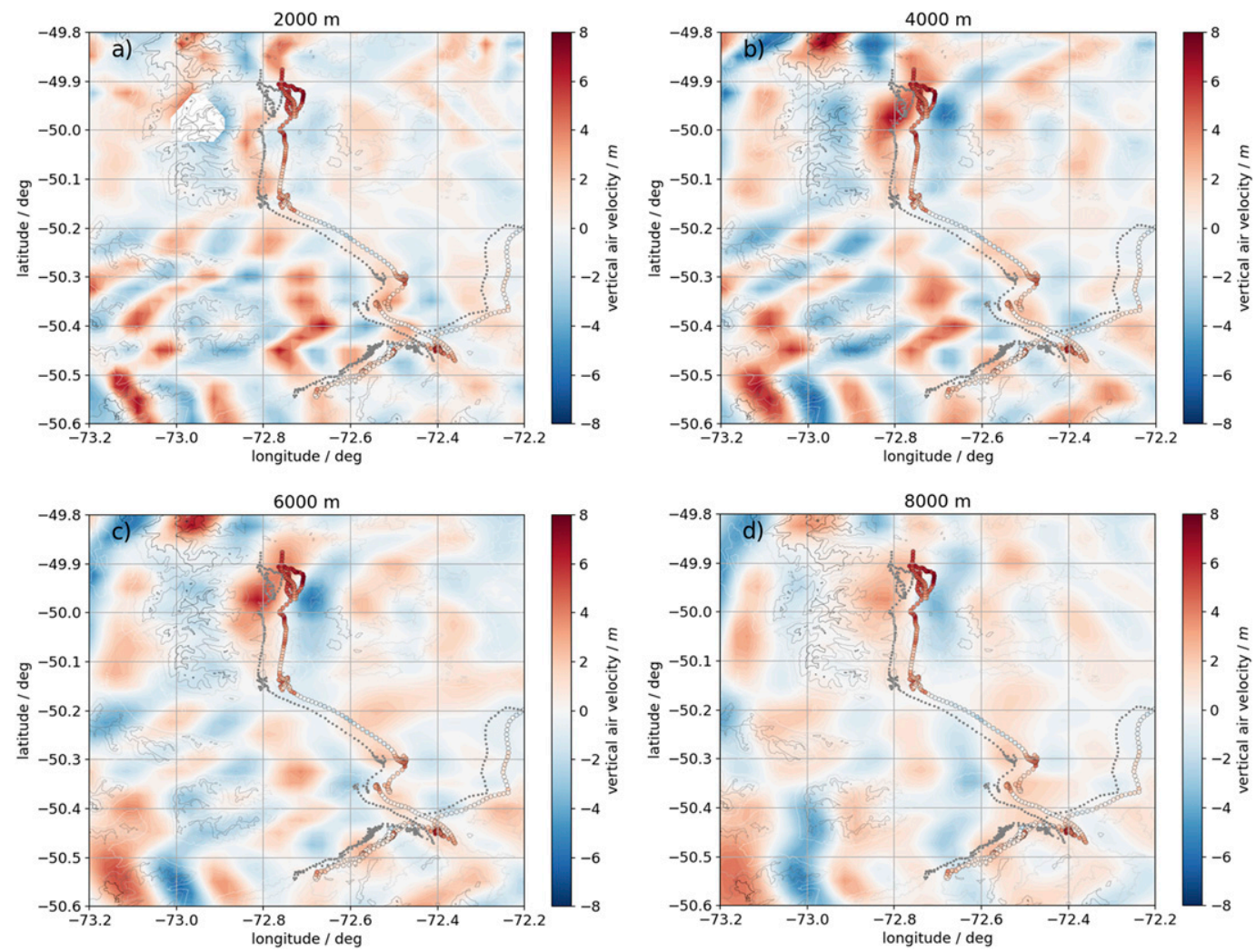

FIG. 11. MetUM output of vertical air velocity in (a) 2000, (b) 4000, (c) 6000, and (d) $8000 \mathrm{~m}$ at 1500 UTC 11 Sep 2019 overlaid with the flight path of D-KKOP. The gray-shaded flight track is the original flight track shifted west by $0.05^{\circ}$. 

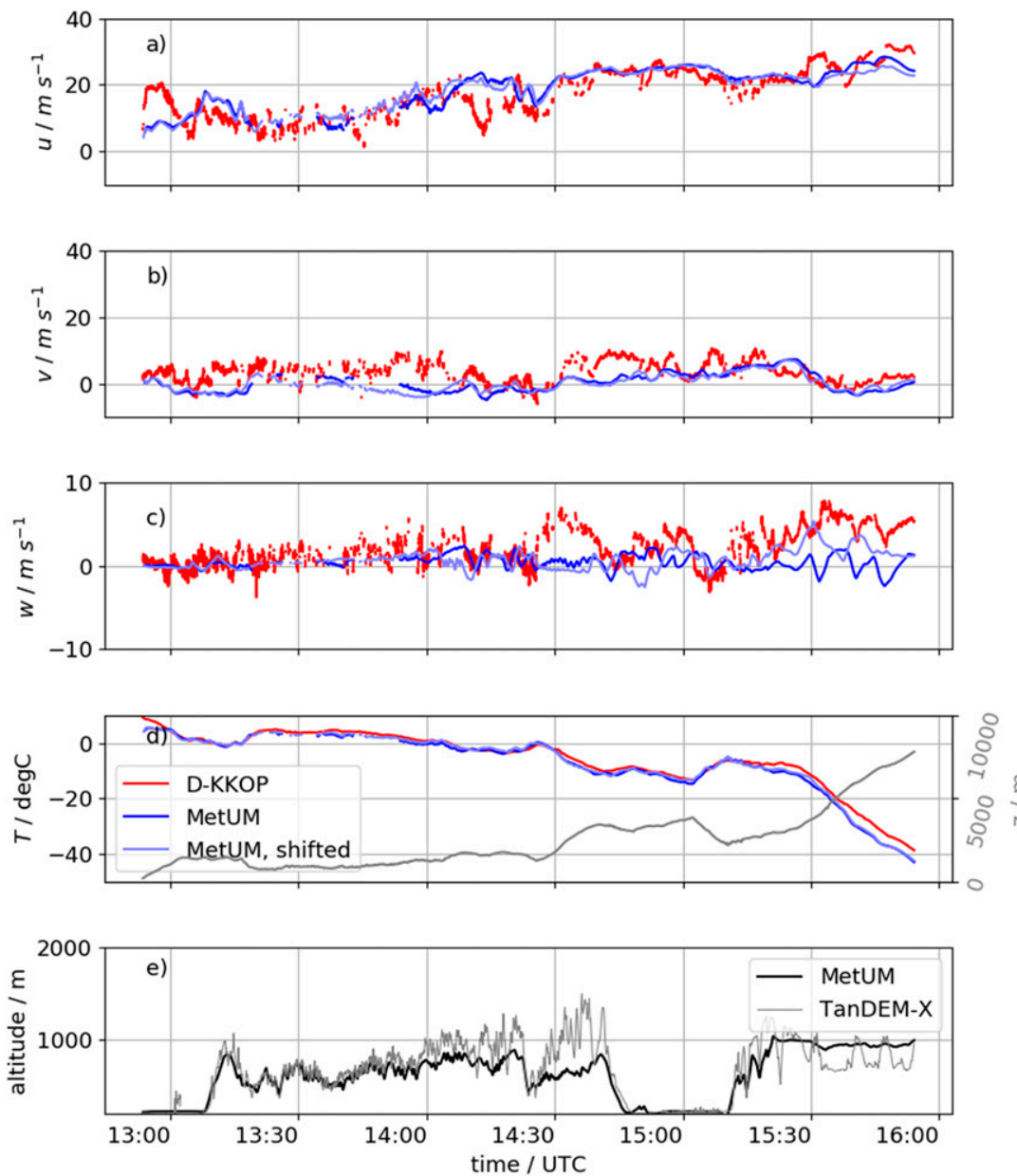
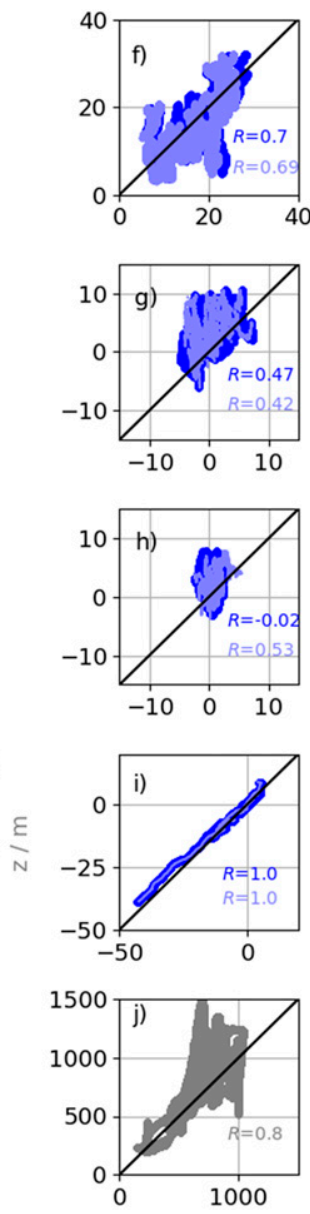

FIG. 12. Comparison of time series and corresponding scatterplots for the three wind components (a),(f) $u$, (b),(g) $v$, and (c),(h) $w$, and (d),(i) temperature $T$ between measurements of D-KKOP and simulation results of MetUM interpolated to the flight track. The light-blue color indicates a modified flight track, shifted west by $0.05^{\circ}$. In (d), the flight altitude $z$ is included with a gray line. (e),(j) The terrain height as it is used by the MetUM model (black, thick line) in comparison to TanDEM-X $90 \mathrm{~m}$ data (gray, thin line). In all scatterplots the MetUM results are on the $x$ axis.

model is highest in this part of the flight. For the period of 1515-1545 UTC, a better agreement between model and observation is found for the shifted flight track. However, the vertical wind of the model output is still lower, showing only 2-4 $\mathrm{m} \mathrm{s}^{-1}$ compared to $4-8 \mathrm{~m} \mathrm{~s}^{-1}$ as measured by D-KKOP. The improvement of the comparison of the shifted flight track to the model for the vertical wind component is also reflected in the correlation coefficient $R$, which increases from $R \approx 0$ to at least $R=0.53$, while the correlation coefficients for the other two wind components decrease slightly (see Fig. 12).

On the day of the case study, a radiosonde released at 1500 UTC sampled the vertical profile of temperature, humidity, and wind speed at approximately the same time as D-KKOP. Figure 13 shows the comparison of radiosonde, D-KKOP, and MetUM. For this comparison, the flight data are averaged in height bins of $100 \mathrm{~m}$. Given the differences of time and location where the radiosonde samples the atmosphere, a good agreement between radiosonde, D-KKOP, and the model is found for wind speed and wind direction. Below $2000 \mathrm{~m}$, D-KKOP had not entered the wave and the flight is characterized by more turbulent conditions and more dynamic flight maneuvers, which leads to more variability in the wind direction measurement and the observed peaks in the vertical profile. At the lowest model levels, below $1200 \mathrm{~m}$, the observations indicate horizontal wind speeds of $15 \mathrm{~m} \mathrm{~s}^{-1}$, whereas only $8 \mathrm{~m} \mathrm{~s}^{-1}$ are found in the model, associated with a wind direction change at $1000 \mathrm{~m}$ altitude, which is not observed by the radiosonde. The temperature profile between model and radiosonde fit quite well, with the largest differences of 2-3 K below $600 \mathrm{~m}$. Measurements of D-KKOP agree well with the radiosonde measurements up to $3500 \mathrm{~m}$ and show some warmer temperatures aloft. We cannot fully answer the question if this deviation is due to the conditions in the mountain waves or if the difference can also be attributed to sensor errors. This also applies to deviations in calculated dewpoint temperature, which is lower for the glider measurements for 

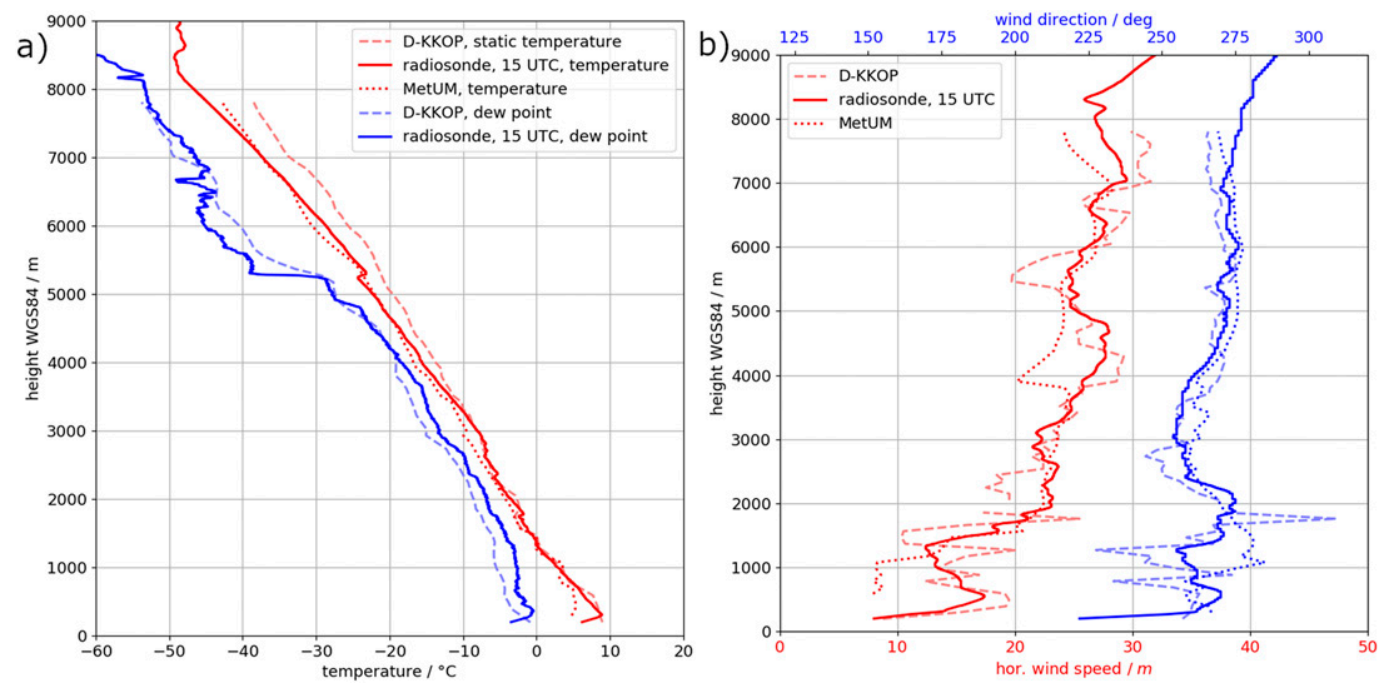

FIG. 13. Vertical profiles of (a) temperature and dewpoint and (b) wind speed and direction for 11 Sep 2019, measured by D-KKOP (dashed lines) and a radiosonde released in El Calafate (solid lines) compared to the MetUM results (dotted lines).

most of the profile, except for an altitude range between 5000 and $7000 \mathrm{~m}$. No model output of humidity was available.

This case study shows how valuable the in situ data are to validate model results on the mesoscale. The overall good performance of the model at a horizontal resolution of $1 \mathrm{~km}$ can be evaluated in detail using wind measurements of the glider and remaining uncertainties and model errors can be quantified. Possible reasons for model errors include the limited vertical, horizontal, and temporal resolution of the model, near-surface quantities (such as winds and stability or dissipation by boundary layer processes) that can determine the wave characteristics, as well as the smooth model orography, which can be seen to differ significantly from TanDEM-X data at locations of highest model errors compared to the aircraft measurements. For a direct comparison of flight data to interpolated model data, it has to be considered that small errors in wave phase can lead to larger errors in the comparison due to the strong horizontal gradients in vertical velocity.

\section{Conclusions and outlook}

For the purpose of mountain wave research, we developed and deployed a measurement system for wind, temperature, and humidity, including a five-hole flow probe to resolve turbulent fluctuations, on a Stemme S10-VT motor glider aircraft. We show that the newly developed sensor suite of small size and low weight provides valuable data of atmospheric flow and turbulence in mountain waves. An installation of a dual GNSS antenna, calibration of the flow probe at multiple calibration points in the wind tunnel, and in-flight calibration of the whole system were performed to cope with the special conditions of wave soaring flights and minimize systematic errors in the wind measurements. The overall accuracy of wind vector measurements is estimated to be on the order of $0.5 \mathrm{~m} \mathrm{~s}^{-1}$.

A dataset of 30 flights was collected in the time between September 2019 and January 2020 and contains soaring flights of over $10 \mathrm{~h}$ duration as well as short transit flights without wave activity in the atmosphere. The discrimination between flight periods with engine support and without engine support allows us to evaluate if the flow probe turbulence measurements are significantly affected by the engine. We show that, except for the generally lower overall turbulence in wave soaring flights, no deformation of the energy spectrum is introduced during motor flights either by backwash or vibrations.

The conditions under which soaring can successfully be performed in the lee of the Andes are documented by the comparison of soaring flight periods to motor flight periods. The high horizontal wind speeds up to $50 \mathrm{~m} \mathrm{~s}^{-1}$, the narrow range of wind directions $\left(250^{\circ}-290^{\circ}\right)$, the low temperatures down to $-50^{\circ} \mathrm{C}$ and low relative humidity in the updrafts, as well as the preferred higher altitude compared to the motor flight periods are characteristic features that can be deduced from the histograms. Beyond that, the data feature unique in situ measurements of mountain wave flow. As an example, we showed the distribution of vertical air velocity, TKE, and its dissipation rate. In the time series of all flights we see that during wave soaring, turbulence is generally weak with short outbursts of high turbulence. According to the categorization of mountain waves by Holmboe and Klieforth (1957), the observed vertical air velocities suggest that $40.6 \%$ of the soaring flights are in weak, $14.1 \%$ in moderate and still $0.4 \%$ in strong mountain waves. Very low TKE dissipation rates below $10^{-5} \mathrm{~m}^{2} \mathrm{~s}^{-3}$ and TKE below $0.5 \mathrm{~m}^{2} \mathrm{~s}^{-2}$ are dominant in the quasi laminar flow of the wave lift.

Using the example of the flight on 11 September 2019, we show the value of the data for validation of mesoscale NWP models. The comparison of flight data with model data reveals a coincidence between the updrafts in the flight track and predicted waves at $1 \mathrm{~km}$ horizontal model resolution. It also shows that remaining model uncertainties on small scales can be identified with the data. In the presented case, the 


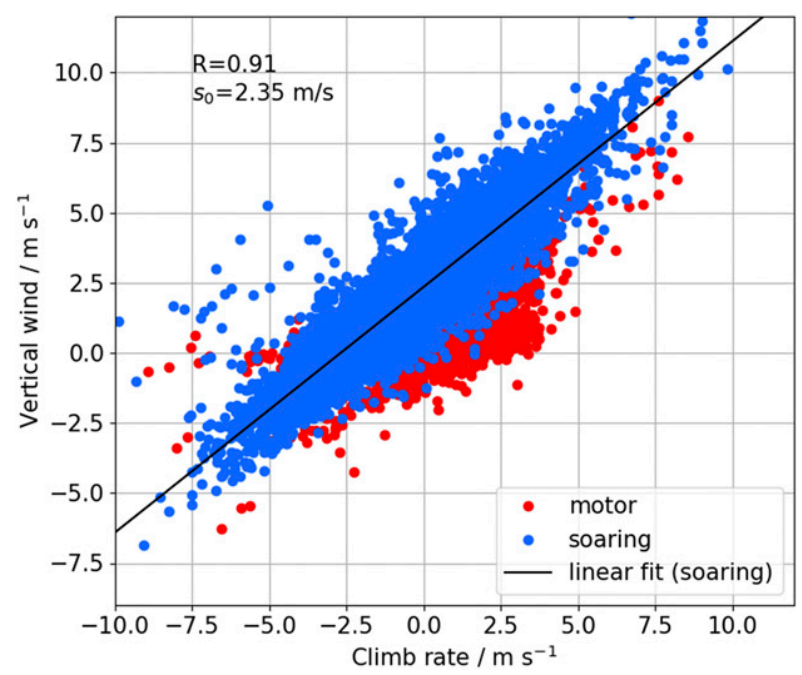

FIG. A1. Scatterplot of measured vertical air velocity vs measured climb rate of the Stemme aircraft.

location of a wave lift that was used to gain almost $4 \mathrm{~km}$ altitude in $30 \mathrm{~min}$ flight time is found approximately $4 \mathrm{~km}$ upstream of the flight track in the model and contains $2-4 \mathrm{~m} \mathrm{~s}^{-1}$ weaker vertical winds. In those regions where the smooth model orography differs significantly from the real orography below the flight path, the largest differences between modeled and measured vertical air velocity are found.

In the future, extended analysis and comparison of individual flights or even the whole dataset could help to further validate models' representation of gravity waves in the troposphere. To improve measurements with the system, a better airflow around the temperature sensor needs to be established and in-flight calibration should be improved and validated to further reduce the uncertainty of the wind measurements.

Acknowledgments. We thank two anonymous reviewers and Prof. Dr. Jörg M. Hacker for their critical comments that helped to improve this manuscript. We acknowledge the support of Consejo Nacional de Investigaciones Científicas y Técnicas (CONICET) and particularly Alejandro de la Torre, who helped in many ways to make this campaign a success. We thank the staff of El Calafate airport and Empresa Argentina de Navegación (EANA) for making it possible to operate the motor glider from the airport in El Calafate and in Argentinian airspace. A special thanks goes to Patrick and Sandra who hosted us at the Brillos Patagónicos cabanas. They allowed us to launch radiosondes from there, and helped us with many professional and personal issues. Last but not least, we thank Markus Garhammer for operating the radiosondes and being a great asset for the campaign. This work was partly funded by the German Ministry for Education and Research under Grants 01 LG 1907 (project WASCLIM) in the frame of the Role of the Middle Atmosphere in Climate (ROMIC) program as well as by internal funds of the German Aerospace Center. Collaboration between SG and AvN was established in the framework of the ISSI Team "New Quantitative Constraints on
OGW Stress and Drag" at the International Space Science Institute in Bern, Switzerland.

Data availability statement. The data are available from the authors upon request.

\section{APPENDIX}

\section{Aircraft Sink Rate}

A glider's sink rate defines how much vertical air velocity is necessary to gain altitude. It depends on airspeed and wing loading and can thus not be determined universally. Looking at the measured climb rate of D-KKOP versus the vertical wind reveals that on average, a vertical air velocity of $2.35 \mathrm{~m} \mathrm{~s}^{-1}$ is necessary to compensate the sink rate of the aircraft during the wave soaring flights that were analyzed in this study (see Fig. A1).

\section{REFERENCES}

Bougeault, P., and Coauthors, 2001: The MAP Special Observing Period. Bull. Amer. Meteor. Soc., 82, 433-462, https://doi.org/ 10.1175/1520-0477(2001)082<0433:TMSOP >2.3.CO;2.

Brahic, C., 2012: The Perlan project: Flying on the thinnest air. New Sci., 213, 34-37, https://doi.org/10.1016/S0262-4079(12)60056-6.

Bramberger, M., A. Dörnbrack, H. Wilms, F. Ewald, and R. Sharman, 2020: Mountain-wave turbulence encounter of the research aircraft HALO above Iceland. J. Appl. Meteor. Climatol., 59, 567-588, https://doi.org/10.1175/JAMC-D-19-0079.1.

Bush, M., and Coauthors, 2020: The first Met Office Unified Model-JULES regional atmosphere and land configuration, RAL1. Geosci. Model Dev., 13, 1999-2029, https:/doi.org/ 10.5194/gmd-13-1999-2020.

Crawford, T. L., and R. J. Dobosy, 1992: A sensitive fast-response probe to measure turbulence and heat flux from any airplane. Bound.-Layer Meteor., 59, 257-278, https://doi.org/10.1007/ BF00119816.

Dörnbrack, A., and Coauthors, 2020: Unusual appearance of mother-of-pearl clouds above El Calafate, Argentina $\left(50^{\circ} 21^{\prime} \mathrm{S}\right.$, $\left.72^{\circ} 16^{\prime} \mathrm{W}\right)$. Weather, 75, 378-388, https://doi.org/10.1002/ wea.3863.

Fritts, D. C., and Coauthors, 2016: The Deep Propagating Gravity Wave Experiment (DEEPWAVE): An airborne and groundbased exploration of gravity wave propagation and effects from their sources throughout the lower and middle atmosphere. Bull. Amer. Meteor. Soc., 97, 425-453, https://doi.org/ 10.1175/BAMS-D-14-00269.1.

Gohm, A., and Coauthors, 2009: Air pollution transport in an Alpine valley: Results from airborne and ground-based observations. Bound.-Layer Meteor., 131, 441-463, https://doi.org/ 10.1007/s10546-009-9371-9.

Grubišić, V., and J. M. Lewis, 2004: Sierra Wave Project revisited: 50 years later. Bull. Amer. Meteor. Soc., 85, 1127-1142, https:// doi.org/10.1175/BAMS-85-8-1127.

— , and Coauthors, 2008: The Terrain-Induced Rotor Experiment: A field campaign overview including observational highlights. Bull. Amer. Meteor. Soc., 89, 1513-1534, https://doi.org/10.1175/ 2008BAMS2487.1.

Guinamard, A., 2018: Ellipse, Ekinox and Apogee-High performance inertial sensors. SBG Systems Tech. Rep. SBGTECHRM.1.2, $52 \mathrm{pp}$. 
Hacker, J., and T. Crawford, 1999: The BAT-Probe: The ultimate tool to measure turbulence from any kind of aircraft (or sailplane). Tech. Soaring, 23, 43-46.

—, R. Heise, K. Ohlmann, W.-D. Herold, R. Gaissmaier, R. Hub, and E. Alvarez, 2007: Measuring mountain waves and turbulence at up to $12 \mathrm{~km}$ altitude over the Andes in South America using an instrumented motorised glider. 14th National AMOS Conf., Adelaide, Australia, AMOS.

Holmboe, J., and H. Klieforth, 1957: Investigation of mountain lee waves and the air flow over the Sierra Nevada. University of California Final Rep. Contract AF 19(604)-728, 283 pp.

Kolmogorov, A., 1991: The local structure of turbulence in incompressible viscous fluid for very large Reynolds numbers. Proc. Roy. Soc. London, 434A, 9-13, https://doi.org/10.1098/ rspa.1991.0075.

Küttner, J., 1938: Moazagotl und Föhnwelle. Beitr. Phys. Freien Atmos., 25, 79-114.

Kuettner, J., 1959: The rotor flow in the lee of mountains. AFCRC Tech. Note 58-626, 28 pp.

- and C. Jenkins, 1953: Flight aspects of the mountain wave. AFCRC Tech. Rep. 53-36, 19 pp.

Ledderhos, C., R. Heise, C. Gammel, and A. Gens, 2015: "Inflight"Messungen der Sauerstoffsättigung bei Höhenflügen im Himalaya und den französischen Alpen im Rahmen des "Mountain Wave Project" (MWP). Wehrmed. Monatsschr., 9, 286-292.

Lenschow, D., Ed., 1986: Probing the Atmospheric Boundary Layer. Amer. Meteor. Soc., 269 pp.

Lin, Y., 2010: Mesoscale Dynamics. Cambridge University Press, $646 \mathrm{pp}$.

Lindemann, C., R. Heise, and W.-D. Herold, 2008: Lee waves in the Andes region, Mountain Wave Project (MWP) of OSTIV. Tech. Soaring, 32, 93-96.

Mallaun, C., A. Giez, and R. Baumann, 2015: Calibration of 3-D wind measurements on a single-engine research aircraft. Atmos. Meas. Tech., 8, 3177-3196, https://doi.org/10.5194/amt8-3177-2015.

Metzger, S., W. Junkermann, K. Butterbach-Bahl, H. P. Schmid, and T. Foken, 2011: Corrigendum to "Measuring the 3-D wind vector with a weight-shift microlight aircraft" published in Atmos. Meas. Tech., 4, 1421-1444, 2011. Atmos. Meas. Tech., 4, 1515-1539, https://doi.org/10.5194/amt-4-1515-2011.

Neininger, B., and J. M. Hacker, 2011: Manned or unmanned-Does this really matter? Int. Arch. Photogramm. Remote Sens. Spat. Inf. Sci, 38-1, 223-228, https://doi.org/10.5194/isprsarchivesXXXVIII-1-C22-223-2011.

_ W. Fuchs, and M. Baeumle, 2001: A small aircraft for more than just ozone: MetAir's 'DIMONA' after ten years of evolving development. 11th Symp. on Meteorological Observations and Instrumentation, Albuquerque, NM, Amer. Meteor. Soc., $123-128$.

Ohlmann, K., 2011: The OSTIV Küttner Flight report: Klaus Ohlmann's 1,677 and $2,138 \mathrm{~km}$ free straight distance flights. Tech. Soaring, 35, 96-100.

Rapp, M., and Coauthors, 2021: SOUTHTRAC-GW: An airborne field campaign to explore gravity wave dynamics at the world's hotspot. Bull. Amer. Meteor. Soc., https://doi.org/10.1175/ BAMS-D-20-0034.1, in press.

Rautenberg, A., and Coauthors, 2019: The Multi-Purpose Airborne Sensor Carrier MASC-3 for wind and turbulence measurements in the atmospheric boundary layer. Sensors, 19, 2292, https://doi.org/10.3390/s19102292.

Rizzoli, P., and Coauthors, 2017: Generation and performance assessment of the global TanDEM-X digital elevation model. ISPRS J. Photogramm. Remote Sens., 132, 119-139, https:// doi.org/10.1016/j.isprsjprs.2017.08.008.

Rotach, M. W., and Coauthors, 2004: Turbulence structure and exchange processes in an Alpine valley: The Riviera project. Bull. Amer. Meteor. Soc., 85, 1367-1386, https://doi.org/ 10.1175/BAMS-85-9-1367.

Sharman, R., and T. Lane, 2016: Aviation Turbulence: Processes, Detection, Prediction. Springer International Publishing, 538 pp.

Smith, R. B., 2019: 100 years of progress on mountain meteorology research. A Century of Progress in Atmospheric and Related Sciences: Celebrating the American Meteorological Society Centennial, Meteor. Monogr., No. 59, Amer. Meteor. Soc., https://doi.org/10.1175/AMSMONOGRAPHS-D-18-0022.1.

Strauss, L., S. Serafin, S. Haimov, and V. Grubišić, 2015: Turbulence in breaking mountain waves and atmospheric rotors estimated from airborne in situ and Doppler radar measurements. Quart. J. Roy. Meteor. Soc., 141, 3207-3225, https://doi.org/10.1002/qj.2604.

van den Kroonenberg, A. C., T. Martin, M. Buschmann, J. Bange, and P. Vörsmann, 2008: Measuring the wind vector using the autonomous mini aerial vehicle $\mathrm{M}^{2} \mathrm{AV}$. J. Atmos. Oceanic Technol., 25, 1969-1982, https://doi.org/10.1175/ 2008JTECHA1114.1.

van Niekerk, A., T. G. Shepherd, S. B. Vosper, and S. Webster, 2016: Sensitivity of resolved and parametrized surface drag to changes in resolution and parametrization. Quart. J. Roy. Meteor. Soc., 142, 2300-2313, https://doi.org/10.1002/qj.2821.

Vosper, S. B., A. van Niekerk, A. Elvidge I. Sandu, and A. Beljaars, 2020: What can we learn about orographic drag parametrisation from high-resolution models? A case study over the Rocky Mountains. Quart. J. Roy. Meteor. Soc., 146, 979-995, https:// doi.org/10.1002/qj.3720.

Wildmann, N., S. Ravi, and J. Bange, 2014: Towards higher accuracy and better frequency response with standard multi-hole probes in turbulence measurement with remotely piloted aircraft (RPA). Atmos. Meas. Tech., 7, 1027-1041, https:// doi.org/10.5194/amt-7-1027-2014.

_ - G. A. Rau, and J. Bange, 2015: Observations of the early morning boundary-layer transition with small remotely-piloted aircraft. Bound.-Layer Meteor., 157, 345-373, https://doi.org/ 10.1007/s10546-015-0059-z.

Wilms, H., M. Bramberger, and A. Dörnbrack, 2020: Observation and simulation of mountain wave turbulence above Iceland: Turbulence intensification due to wave interference. Quart. J. Roy. Meteor. Soc., 146, 3326-3346, https://doi.org/10.1002/ qj.3848. 